\title{
Eating disorders in adolescent and young adult males: prevalence, diagnosis, and treatment strategies
}

This article was published in the following Dove Press journal:

Adolescent Health, Medicine and Therapeutics

\author{
Christine A Limbers \\ L Adelyn Cohen \\ Bethany A Gray \\ Department of Psychology and \\ Neuroscience, Baylor University, \\ Waco, TX, USA
}

\begin{abstract}
Males have largely been underrepresented in the eating disorder (ED) peer-reviewed literature. The current review paper examines prevalence rates, ED symptom presentation, and assessment and treatment strategies relevant to adolescent and young adult males. Adolescent and young adult males often report a greater desire to be bigger and more muscular compared to their female counterparts. Due to concerns that contemporary ED assessment tools are over reliant on items that evaluate stereotypically feminine indicators of ED pathology, male-specific ED measures, such as the Eating Disorder Assessment for Men, have been developed. Further validation work is necessary to establish the psychometric properties of these male-specific measures, particularly in adolescent male populations. Attention to a heightened prevalence of comorbid substance abuse disorders and the role that competitive sports play in perpetuating ED pathology are two factors that have been identified as important in the treatment of adolescent and young adult males with EDs. Keywords: males, eating disorders, assessment, treatment, prevalence
\end{abstract}

\section{Eating disorders}

The Diagnostic and Statistical Manual of Mental Disorders 5th Edition (DSM-5) defines eating disorders (EDs) as a group of illnesses marked by severe disturbances in eating behaviors. ${ }^{1}$ The use of inappropriate weight control techniques is a key feature of EDs. ${ }^{2}$ DSM-5 recognizes anorexia nervosa, bulimia nervosa, binge eating disorder, and other specified/unspecified eating disorder as distinct disorders within this group. ${ }^{1}$

To date, males have largely been underrepresented in the ED peer-reviewed literature. ${ }^{3}$ Two recent systematic reviews highlight ED prevalence rates among males and important considerations related to symptom presentation and diagnosis. ${ }^{3,4}$ These review papers focused on males across the life span and did not specifically address treatment strategies. The purpose of the present review paper was to examine prevalence rates, ED symptom presentation, and assessment and treatment strategies relevant to adolescent and young adult males.

\section{Prevalence}

Although EDs are often thought of as feminine illnesses, epidemiological studies indicate that males are also at-risk for developing EDs. ${ }^{5-7}$ In a national sample of adolescents and young adults in the United States, Lipson and Sonneville found 5.5\% of males manifested elevated ED risk. ${ }^{8}$ Flament et $\mathrm{al}^{9}$ found that $1.1 \%$ of adolescent males in their Canadian sample exhibited a subthreshold ED, which was associated with significant impairments in psychosocial functioning. The lifetime prevalence of
Correspondence: Christine A Limbers Department of Psychology and Neuroscience, Baylor University, One Bear Place \#97334, Waco, TX 76798, USA

Tel +I 2547102485

Email Christine_Limbers@baylor.edu 
DSM-5 EDs in a Dutch sample of young adult males was $1.2 \%{ }^{7}$ Similarly, the prevalence of DSM-5 EDs was $1.2 \%$ and $2.2 \%$, respectively, in community samples of adolescent males in Australia and Canada. ${ }^{6,9}$ Allen et $\mathrm{al}^{6}$ observed a significant increase in the prevalence of bulimia nervosa between the ages 14 and 20 years in their sample of Australian males. Existing prevalence rates likely underestimate the number of males affected by EDs, as the social stigma associated with ED pathology in males often causes them to minimize or deny the presence of symptoms. ${ }^{10,11}$

\section{Male ED symptom presentation}

Adolescence and young adulthood are peak periods for the development of EDs. ${ }^{12}$ Up to $30 \%$ of adolescent males in Australia and the United States report body dissatisfaction ${ }^{13}$ and utilization of unhealthy weight control behaviors. ${ }^{14}$ Adolescent and young adult males who present for ED treatment, especially for binge ED, generally report less shape and weight concern, drive for thinness, and body dissatisfaction than their female counterparts. ${ }^{15-17}$ Whereas body dissatisfaction in white females is usually associated with a desire to be thinner, adolescent and young adult male concerns typically center around being "bigger" and more muscular. ${ }^{18,19}$ An exception to this is males with anorexia nervosa who may be more likely to have concerns about thinness and not muscularity. ${ }^{20}$

Muscle dysmorphic disorder, added as a type of body dysmorphic disorder in DSM-5, describes individuals who have a preoccupation with their appearance and are concerned that they are not sufficiently large and muscular. ${ }^{1}$ Individuals with muscle dysmorphic disorder often engage in activities intended to enhance muscularity including dieting, weightlifting, and steroid drug use. ${ }^{21}$ Given that adolescent and young adult males with EDs often present with concerns about being insufficiently large and muscular, it has been suggested that muscle dysmorphic disorder would be better classified in the DSM as a type of ED. ${ }^{22,23}$

Other sex differences in ED pathology have been reported in the peer-reviewed literature. Adolescent and young adult males who present with bulimic symptoms are less likely to engage in dieting, laxative use, and self-induced vomiting than females. ${ }^{24-26}$ Compared to females, adolescent and young adult males are less likely to report eating in response to negative emotion, experiencing a sense of loss of control when binge eating, and restricting their food intake in response to body dissatisfaction..$^{25,27,28}$ Sexuality has also been identified as a male-specific risk factor for the development of EDs, ${ }^{29-31}$ in that adolescent and young adult males who are gay or bisexual exhibit higher rates of ED pathology. There are mixed findings with regard to exercise with some research supporting young adult males with EDs are more likely than females to engage in excessive exercise ${ }^{32}$ and other studies not supporting this finding. ${ }^{33,34}$

\section{Assessment}

The Eating Disorder Examination (EDE) is considered the "gold standard" for the assessment of EDs. ${ }^{35}$ This semistructured diagnostic interview has 4 subscales (Dietary Restraint, Eating Concern, Shape Concern, Weight Concern) that assess the frequency and intensity of behavioral and cognitive symptoms associated with EDs during the last 28 days (last 3 months for diagnostic items). The EDE has versions developed specifically for use with children and adolescents ${ }^{36}$ and their parents. ${ }^{37}$ Self-report questionnaires including the Eating Disorder Examination Questionnaire, Eating Disorder Diagnostic Scale, and Eating Disorder Inventory are also utilized to evaluate ED symptomatology in adolescents and young adults; however, self-report questionnaires may yield less valid data in comparison to semi-structured diagnostic interviews like the EDE, as the latter provides an opportunity for an evaluator to explain the meaning of terms. ${ }^{38}$

Since contemporary ED measures were created and normed predominantly for female populations, a major criticism of these measures has been their overreliance on items that capture stereotypically feminine indicators of ED pathology. ${ }^{26,39,40}$ Darcy et $\mathrm{al}^{41}$ compared responses on the EDE diagnostic interview across a matched sample of male and female adolescents diagnosed with anorexia nervosa. In comparison to females, males in their sample scored significantly lower on the EDE Global Score and Shape Concern and Weight Concern subdomains. The effect sizes for these differences were in the small to moderate range (ES range=0.29-0.40). An investigation of specific items on the EDE revealed that adolescent males were less likely than females to endorse wanting a flat or empty stomach, being uncomfortable while eating in front of others, eating in secret, and a desire to lose weight. ${ }^{41}$ Finally, while Cronbach's alphas were similar and well within the acceptable range for both adolescent males and females on the EDE Global Score (males=0.93; females $=0.95$ ), Cronbach's alphas for the Dietary Restraint (males $=0.689$; females $=0.841$ ) and Eating Concern (male $=0.661$; females $=0.802$ ) subdomains were lower for adolescent males and below the 0.70 cutoff typically recommended for making group comparisons. Taken as a whole, these data underscore the need for clinicians to use caution when utilizing contemporary ED measures to make 
a definitive diagnosis or assess symptom severity within adolescent and young adult male populations. Additional research is needed to establish the psychometric properties of existing ED measures in male populations, particularly for adolescent males.

Given the potential limitations of utilizing contemporary ED measures with male populations, some researchers have advocated for the development of male-specific ED measures. ${ }^{42}$ Stanford and Lemberg ${ }^{42}$ created the Eating Disorder Assessment for Men (EDAM) to address this need. The EDAM is a 50 -item measure that assesses behavioral and cognitive symptoms specific to males with EDs across five domains (food issues, weight concerns, exercise issues, body image/appearance concerns, disordered eating habits). The development of the EDAM involved a comprehensive literature review and focus groups/interviews with clinicians and experts in the field. ${ }^{42}$ The initial validation work of this measure was conducted with 108 adult patients with EDs and addictions ( 78 men and 30 women) recruited from residential treatment facilities and a comparison group of 45 males without an ED. The EDAM accurately predicted an ED in 82.1\% of the adult males and the total score demonstrated a Cronbach's alpha well within the acceptable range (alpha $=0.91){ }^{42}$ A similar study revealed significant differences between adult males and females with EDs on the EDAM total score (males 70.64; females $83.87 ; p=0.013) .{ }^{43}$ While the early validation work of the EDAM has yielded promising findings, further research is needed to establish the psychometric properties of the EDAM and other male-specific measures including the Male Body Image Concerns Scale and the Male Body Checking Questionnaire, ${ }^{10}$ particularly for male adolescent populations.

\section{Treatment strategies}

As highlighted in a recent review by Lock, family-based behavioral treatment is the only intervention that has been delineated as a well-established treatment for adolescents with EDs. ${ }^{44}$ Enhanced cognitive behavioral therapy, dialectical behavioral therapy, cognitive training, and interpersonal psychotherapy have been classified as experimental for the treatment of EDs in adolescents. ${ }^{44}$ For young adults with anorexia nervosa, bulimia nervosa, and binge ED, cognitive behavioral therapy and interpersonal psychotherapy are the most established treatments. ${ }^{45}$ There is preliminary research that indicates family-based therapy may also be promising for young adults. ${ }^{46}$ In a study of young adults with anorexia nervosa between the ages of 18 and 26 years, Chen et al found that after receiving 6 months of family-based therapy for young adults, approximately $68 \%$ of participants were no longer underweight $\left(B M I>19 \mathrm{~kg} / \mathrm{m}^{2}\right)$. Although there was a dropout rate of $41 \%$, family-based therapy for young adults led to reductions in ED pathology and improvements in global functioning. ${ }^{46}$

Compared to females, young adult males are less likely to seek treatment for EDs and do so later relative to the onset of their eating pathology. ${ }^{17,47}$ This trend is especially apparent among young adult males from ethnic minority groups and lower socioeconomic backgrounds, despite research indicating equivalent or higher levels of ED pathology among these populations. ${ }^{17}$ Several explanations have been proposed for why males seek treatment for disordered eating later and at lower rates than their female counterparts. For example, adolescent and young adult males may not be as readily aware that their eating and weight control behaviors are pathological due to a perception that EDs mostly affect females. ${ }^{48}$ This misconception may be especially pertinent for males who engage in behaviors such as excessive exercise and binge eating, rather than behaviors more typically associated with EDs, such as self-induced vomiting and extreme dietary restraint. Further, physicians and other health care providers may be less likely to recognize disordered eating symptoms in adolescent and young adult males due to their lower rates of incidence and differences in symptom presentation. ${ }^{47,49}$ Adolescent and young adult males with EDs, particularly anorexia nervosa, often present with higher premorbid weight or a history of overweight/obesity, which can delay identification of the ED and treatment. ${ }^{50,51}$ Most notably, adolescent and young adult males may be less likely to seek treatment than females due to an overall higher degree of shame and stigma related to their EDs. ${ }^{25,47,49}$

Despite research suggesting that adolescent and young adult males have equivalent treatment outcomes to females, ${ }^{16,17,25,26}$ if not superior ones, ${ }^{52}$ a number of studies have sought to understand factors that have the potential to enhance treatment outcomes for males who receive treatment for an ED. Improving interpersonal interactions has been identified as an important target in ED treatments for adolescent and young adult males..$^{47,53}$ Thapliyal et al ${ }^{54}$ reported that therapist characteristics and quality of therapeutic relationships were the most critical factors in the treatment experience of young adult males in ED treatment. Specifically, the use of a collaborative treatment approach and client perception of therapist expertise, caring, and trustworthiness were among the most important factors in males' treatment experiences, while perceived lack of treatment expertise and therapist judgment contributed to a reduction in the desire to 
continue with treatment. ${ }^{54}$ Dearden and Mulgrew ${ }^{47}$ found that trust and comfort in a therapist were the most critical components of ED treatment for young adult males in a qualitative study of service provision for men with EDs. They reported that the majority of men interviewed indicated a preference for a female therapist or did not find the sex of their therapist to be important in their treatment. ${ }^{47}$ Strother et al ${ }^{26}$ reported that weight history, sexual abuse, trauma, sex orientation, body image, exercise abuse, media pressures, and the interplay of depression, EDs, and shame are additional topics that are important to cover in ED treatment with adolescent and young adult males. ${ }^{26}$

Young adult males with EDs have reported that male-only treatment groups help them to feel less isolated than predominantly female groups. ${ }^{47}$ As a result, some researchers have recommended assigning males to different treatment groups than females in order to reduce perceived male stigma and feelings of isolation, as well as to increase males' comfort with disclosing their issues with food and body image. ${ }^{26,55}$ While there may be benefits in male-only treatment groups, these groups may not be feasible in all treatment settings and may not be preferable for some males with EDs. Robinson et $\mathrm{al}^{56}$ reported that one young adult male interviewee in inpatient ED treatment found being in an all-male treatment group less preferable to being in a mixed-sex group. Specifically, he perceived the all-male group to be more competitive and more encouraging of his disordered eating behaviors. ${ }^{56}$

While some studies indicate that adolescent and young adult males with EDs have elevated rates of psychiatric comorbidity compared to females with EDs,,$^{27,51,57}$ other research has not supported this finding. ${ }^{34}$ Adolescent and young adult males with EDs appear to be particularly at-risk for comorbid substance abuse, ${ }^{26,58}$ which may negatively impact their treatment course and outcomes. For example, Elmquist et $\mathrm{al}^{59}$ found that ED symptoms were associated with treatment rejection among adolescent and young adult males in substance abuse treatment. Although treating both eating pathology and substance abuse are essential for positive patient outcomes, it remains unclear whether these symptoms should be treated concurrently or sequentially. ${ }^{26}$

Another factor that may be especially salient for ED treatment in adolescent and young adult males is participation in competitive sports. Adolescent and young adult male athletes have a higher incidence of EDs and general eating pathology than non-athlete males. ${ }^{49,60,61}$ For male athletes who seek treatment, continued participation in sports may lead to poorer treatment outcomes and maintenance of disordered eating behaviors. Specifically, adolescent and young adult males who participate in sports that value leanness or require athletes to fall into certain weight categories may experience pressure from teammates and/or coaches to engage in unhealthy weight control practices. ${ }^{60}$ Even for those adolescent and young adult males who do not receive direct pressure to engage in disordered eating, teams may foster an environment in which such practices are not discouraged. Therefore, incorporating strategies to prevent relapse behaviors and circumvent pressures to engage in unhealthy weight control practices are imperative for adolescent and young adult male athletes in ED treatment.

The PRIDE Body Project is one example of a malespecific intervention developed to diminish the risk of ED pathology among gay adolescent and young adult males. ${ }^{62}$ This peer-led, two-session dissonance-based intervention was adapted from a program developed by Becker et $\mathrm{al}^{63}$ and covered topics including defining the ideal body type among the gay community, understanding where this ideal body type comes from and how it is perpetuated, and discussing the price of pursuing the gay ideal body type. The PRIDE Body Project also involved homework assignments and activities including role plays, verbal challenges in which the thinmuscular ideal was refuted, the development of strategies to challenge negative body talk, and identification of barriers to resist pursuing the ideal body type among the gay community. ${ }^{62}$ In a randomized controlled trial conducted in a university setting, Brown and Keel ${ }^{62}$ found that compared to the waitlist control, the PRIDE Body Project was associated with significantly greater decreases in body dissatisfaction, drive for muscularity, self-objectification, partner objectification, body-ideal internalization, dietary restraint, and bulimic symptoms for gay adolescent and young adult male participants. ${ }^{62}$ These treatment gains were maintained at 4-week follow-up with the exception of reductions in body-ideal internalization. The program also received high acceptability ratings from participants. ${ }^{62}$ While the PRIDE Body Project represents one illustration of tailoring an ED prevention program to the unique characteristics of a male population, future research is needed to determine whether male-specific interventions like the PRIDE Body Project yield enhanced outcomes for adolescent and young adult males at-risk for developing ED pathology.

\section{Conclusion}

Males have largely been underrepresented in the ED peerreviewed literature. ${ }^{5}$ Symptom presentation can vary between adolescent and young adult males and females with EDs, including males (especially those with an ED other than 
anorexia nervosa) reporting a greater desire to be bigger and more muscular and endorsing less shape and weight concern, drive for thinness, and body dissatisfaction than their female counterparts. ${ }^{15-18}$ Contemporary ED assessment tools, including the EDE, have been criticized for their overreliance on items that evaluate stereotypically feminine indicators of ED pathology. ${ }^{26,39,40}$ Male-specific ED measures, such as the EDAM, have been developed for use with male populations, although further validation work is needed to establish the psychometric properties of these measures, particularly with adolescent male populations. While young adult males are less likely to seek treatment for their EDs and do so later relative to the onset of their eating pathology, researchers have sought to understand factors that enhance treatment outcomes for males who receive treatment for an ED. ${ }^{17,47}$ Attention to a heightened prevalence of comorbid substance abuse disorders and the role that competitive sports play in perpetuating ED pathology are two factors that have been identified in the peer-reviewed literature. ${ }^{26,60}$ Additional research is needed to elucidate whether male-specific interventions like the PRIDE Body Project yield enhanced outcomes for adolescent and young adult males with EDs or at-risk for developing ED pathology.

\section{Disclosure}

The authors report no conflicts of interest in this work.

\section{References}

1. American Psychiatric Association. Diagnostic and Statistical Manual of Mental Disorders. 5th ed. Washington, DC: American Psychiatric Association; 2013.

2. Jacobi C, Hayward, C, de Zwaan M, Kraemer HC, Agras WS. Coming to terms with risk factors for eating disorders: application of risk terminology and suggestions for a general taxonomy. Psychol Bull. 2004;130(1):19-65.

3. Murray SB. Nagata JM, Griffiths S, et al. The enigma of male eating disorders: a critical review and synthesis. Clin Psychol Rev. 2017;57(1):1-11.

4. Lavender JM, Brown TA, Murray SB. Men, muscles, and eating disorders: an overview of traditional and muscularity-oriented disordered eating. Curr Psychiatry Rep. 2017;19(6):32.

5. Stice E, Marti CN, Rohde P. Prevalence, incidence, impairment, and course of the proposed DSM-5 eating disorder diagnoses in an 8-year prospective community study of young women. J Abnorm Psychol. 2013;122(2):445-457.

6. Allen KL, Byrne SM, Oddy WH, Crosby RD. DSM-IV-TR and DSM-5 eating disorders in adolescents: prevalence, stability, and psychosocial correlates in a population-based sample of male and female adolescents. J Abnorm Psychol. 2013;122(3):720-732.

7. Smink FR, van Hoeken D, Oldehinkel AJ, Hoek HW. Prevalence and severity of DSM-5 eating disorders in a community cohort of adolescents. Int J Eat Disord. 2014;47(6):610-619.

8. Lipson SK, Sonneville KR. Eating disorder symptoms among undergraduate and graduate students at 12 U.S. Colleges and Universities. Eat Behav. 2017;24:81-88.
9. Flament MF, Henderson K, Buchholz A, et al. Weight status and DSM-5 diagnoses of eating disorders in adolescents from the community. $\mathrm{JAm}$ Acad Child Adolesc Psychiatry. 2015;54(5):403-411.

10. Darcy AM, Lin IH. Are we asking the right questions? A review of assessment of males with eating disorders. Eat Disord. 2012;20(5):416-426.

11. Goldstein MA, Alinsky R, Medeiros C. Males with restrictive eating disorders: barriers to their care. J Adolesc Health. 2016;59(4): 371-372.

12. Campbell K, Peebles R. Eating disorders in children and adolescents: state of the art review. Pediatrics. 2014;134(3):582-592.

13. McCabe MP, Ricciardelli LA, Banfield S. Body image, strategies to change muscles and weight, and puberty: do they impact on positive and negative affect among adolescent boys and girls? Eat Behav. 2001;2(2):129-149.

14. Larson NI, Neumark-Sztainer D, Story M. Weight control behaviors and dietary intake among adolescents and young adults: longitudinal findings from project EAT. J Am Diet Assoc. 2009;109(11):1869-1877.

15. American Psychiatric Association. Treatment of patients with eating disorders, third edition. Am J Psychiatry. 2006;163(7):4-54.

16. Fernández-Aranda F, Krug I, Jiménez-Murcia S, et al. Male eating disorders and therapy: a controlled pilot study with one year follow-up. J Behav Ther Exp Psychiatry. 2009;40(3):479-486.

17. Shingleton RM, Thompson-Brenner H, Thompson DR, Pratt EM, Franko DL. Gender differences in clinical trials of binge eating disorder: an analysis of aggregated data. J Consult Clin Psychol. 2015;83(2):382-386.

18. Tylka TL, Subich LM. A preliminary investigation of the eating disorder continuum with men. J Counsel Psychol. 2002;49(2):273-279.

19. McCreary DR, Sasse DK. An exploration of the drive for muscularity in adolescent boys and girls. J Am Coll Health. 2000;48(6):297-304.

20. Field AE, Sonneville KR, Crosby RD, et al. Prospective associations of concerns about physique and the development of obesity, binge drinking, and drug use among adolescent boys and young adult men. JAMA Pediatr. 2014;168(1):34-39.

21. Tod D, Edwards C, Cranswick I. Muscle dysmorphia: current insights. Psychol Res Behav Manag. 2016;9:179-188.

22. Murray SB, Rieger E, Touyz SW, De la Garza García Lic Y. Muscle dysmorphia and the DSM-V conundrum: where does it belong? A review paper. Int J Eat Dis. 2010;43(6):483-491.

23. Murray SB, Touyz S. How do clinicians in the field conceptualise muscle dysmorphia? Adv Eat Disord. 2013;1:207-212.

24. Button E, Aldridge S, Palmer R. Males assessed by a specialized eating disorders service: patterns over time and comparisons with females. Int J Eat Disord. 2008;41(8):758-761.

25. Weltzin TE, Weisensel N, Franczyk D, Burnett K, Klitz C, Bean P. Eating disorders in men: update. J Mens Health Gender. 2005;2:186-193.

26. Strother E, Lemberg R, Stanford SC, Turberville D. Eating disorders in men: underdiagnosed, undertreated, and misunderstood. Eat Disord. 2012;20(5):346-355.

27. Tanofsky MB, Wilfley DE, Spurrell EB, Welch R, Brownell KD. Comparison of men and women with binge eating disorder. Int J Eat Disord. 1997;21(1):49-54.

28. Womble LG, Williamson DA, Martin CK, et al. Psychosocial variables associated with binge eating in obese males and females. Int $J$ Eat Disord. 2001;30(2):217-221.

29. Boisvert JA, Harrell WA. Homosexuality as a risk factor for eating disorder symptomatology in men. J Mens Stud. 2010;17(3):210-225.

30. Feldman MB, Meyer IH. Eating disorders in diverse lesbian, gay, and bisexual populations. Int J Eat Disord. 2007;3(40):218-226.

31. Carlat DJ, Camargo CA Jr, Herzog DB. Eating disorders in males: a report on 135 patients. Am J Psychiatry. 1997;154(8):1127-1132.

32. Lewinsohn PM, Seeley JR, Moerk KC, Striegel-Moore RH. Gender differences in eating disorder symptoms in young adults. Int $J$ Eat Disord. 2002;32(4):426-440.

33. Anderson CB, Bulik CM. Gender differences in compensatory behaviors, weight and shape salience, and drive for thinness. Eat Behav. 2005;5(1):1-11. 
34. Núñez-Navarro A, Agüera Z, Krug I, et al. Do men with eating disorders differ from women in clinics, psychopathology and personality? Eur Eat Disord Rev. 2012;20(1):23-31.

35. Fairburn CG, Wilson GT. Binge Eating: Nature, Assessment, and Treatment. 12th ed. New York, NY: Guilford Press; 1993.

36. Bryant-Waugh RJ, Cooper PJ, Taylor CL, Lask BD. The use of the eating disorder examination with children: a pilot study. Int J Eat Disord. 1996;19(4):391-397.

37. Couturier J, Lock J, Forsberg S, Vanderheyden D, Lee HY. The addition of parent and clinician component to the eating disorder examination for children and adolescents. Int J Eat Disord. 2007;40(5):472-475.

38. Mash EJ, Barkley RA. Assessment of Childhood Disorders. New York, NY: Guildford Press; 2009.

39. Thomas JJ, Roberto CA, Berg KC. The eating disorder examination: a semi-structured interview for the assessment of the specific psychopathology of eating disorders. Adv Eat Disord Theory Res Pract. 2014;2(2):190-203.

40. Smith KE, Mason TB, Murray SB, et al. Male clinical norms and sex differences on the eating disorder inventory (EDI) and Eating Disorder Examination Questionnaire (EDE-Q). Int J Eat Disord. 2017;50(7):769-775.

41. Darcy AM, Doyle AC, Lock J, Peebles R, Doyle P, Le Grange D. The eating disorders examination in adolescent males with anorexia nervosa: how does it compare to adolescent females? Int J Eat Disord. 2012;45(1):110-114.

42. Stanford SC, Lemberg R. Measuring eating disorders in men: development of the eating disorder assessment for men (EDAM). Eat Disord. 2012;20(5):427-436.

43. Stanford SC, Lemberg R. A clinical comparison of men and women on the Eating Disorder Inventory-3 (EDI-3) and the eating disorder assessment for men (EDAM). Eat Disord. 2012;20(5):379-394.

44. Lock J. An update on evidence-based psychosocial treatments for eating disorders in children and adolescents. J Clin Child Adolesc Psychol. 2015;44(5):707-721.

45. Kass AE, Kolko RP, Wilfley DE. Psychological treatments for eating disorders. Curr Opin Psychiatry. 2013;26(6):549-555.

46. Chen EY, Weissman JA, Zeffiro TA, et al. Family-based therapy for young adults with anorexia nervosa restores weight. Int J Eat Disord. 2016;49:701-707.

47. Dearden A, Mulgrew KE. Service provision for men with eating issues in Australia: an analysis of organisations', practitioners', and men's experiences. Aust Soc Work. 2013;66(4):590-606.

48. Räisänen U, Hunt K. The role of gendered constructions of eating disorders in delayed help-seeking in men: a qualitative interview study. BMJ Open. 2014;4(4):e004342.
49. Muise AM, Stein DG, Arbess G. Eating disorders in adolescent boys: a review of the adolescent and young adult literature. J Adolesc Health. 2003;33(6):427-435.

50. Vo M, Lau J, Rubinstein M. Eating disorders in adolescent and young adult males: presenting characteristics. $J$ Adolesc Health. 2016;59(4):397-400.

51. Welch E, Ghaderi A, Swenne I. A comparison of clinical characteristics between adolescent males and females with eating disorders. $B M C$ Psychiatry. 2015;15:45.

52. Støving RK, Andries A, Brixen K, Bilenberg N, Hørder K. Gender differences in outcome of eating disorders: a retrospective cohort study. Psychiatry Res. 2011;186(2-3):362-366.

53. Pettersen G, Wallin K, Björk T. How do males recover from eating disorders? An interview study. BMJ Open. 2016;6(8):e010760.

54. Thapliyal P, Mitchison D, Hay P. Insights into the experiences of treatment for an eating disorder in men: a qualitative study of autobiographies. Behav Sci (Basel). 2017;7(2):E38.

55. Andersen AE, Holman JE. Males with eating disorders: challenges for treatment and research. Psychopharmacol Bull. 1997;33(3):391-397.

56. Robinson KJ, Mountford VA, Sperlinger DJ. Being men with eating disorders: perspectives of male eating disorder service-users. J Health Psychol. 2013;18(2):176-186.

57. Woodside DB, Garfinkel PE, Lin E, et al. Comparisons of men with full or partial eating disorders, men without eating disorders, and women with eating disorders in the community. Am J Psychiatry. 2001;158(4):570-574.

58. Barry DT, Grilo CM, Masheb RM. Gender differences in patients with binge eating disorder. Int J Eat Disord. 2002;31(1):63-70.

59. Elmquist J, Shorey RC, Anderson SE, Temple JR, Stuart GL. The relationship between eating disorder symptoms and treatment rejection among young adult men in residential substance use treatment. Subst Abuse. 2016;10:39-44.

60. Baum A. Eating disorders in the male athlete. Sports Med. 2006;36(1): $1-6$.

61. Bratland-Sanda S, Sundgot-Borgen J. Eating disorders in athletes: overview of prevalence, risk factors and recommendations for prevention and treatment. Eur J Sport Sci. 2013;13(5):499-508.

62. Brown TA, Keel PK. A randomized controlled trial of a peer co-led dissonance-based eating disorder prevention program for gay men. Behav Res Therapy. 2015;74:1-10.

63. Becker CB, Smith LM, Ciao AC. Reducing eating disorder risk factors in sorority members: a randomized trial. Behav Therapy. 2005;36: 245-253.
Adolescent Health, Medicine and Therapeutics

Publish your work in this journal

Adolescent Health, Medicine and Therapeutics is an international, peer-reviewed, open access journal focusing on health, pathology, and treatment issues specific to the adolescent age group. All aspects of health maintenance, preventative measures and disease treatment interventions are addressed within the journal and practitioners from all disciplines are

\section{Dovepress}

invited to submit their work as well as healthcare researchers and patient support groups. This journal is included in PubMed. The manuscript management system is completely online and includes a very quick and fair peer-review system. Visit http://www.dovepress.com/testimonials. php to read real quotes from published authors. 